\title{
Evaluation of isolation method in remaining of differentiation potential of perivascular human umbilical cord mesenchymal stem cells toward male germ cell-like
}

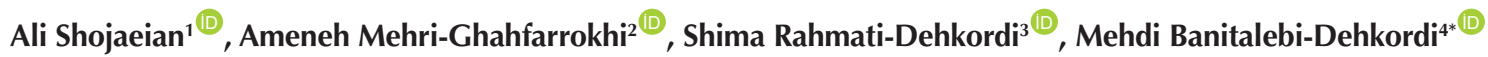 \\ ${ }^{1}$ Research Center for Molecular Medicine, Faculty of Medicine, Hamadan University of Medical Sciences, Hamadan, Iran \\ ${ }^{2}$ Department of Molecular Medicine, School of Advanced Technologies, Shahrekord University of Medical Sciences, \\ Shahrekord, Iran \\ ${ }^{3}$ Cellular and Molecular Research Center, Research Institute for Health Development, Kurdistan University of Medical \\ Sciences, Sanandaj, Iran \\ ${ }^{4}$ Cellular and Molecular Research Center, Basic Health Sciences Institute, Shahrekord University of Medical Sciences, \\ Shahrekord, Iran
}

*Corresponding Author: Mehdi Banitalebi-Dehkordi, Cellular and Molecular Research Center, Basic Health Sciences Institute, Shahrekord University of Medical Sciences, Rahmatieh, Shahrekord, Iran. Phone: +983833346692, Email: mehdibanitalebi@ gmail.com

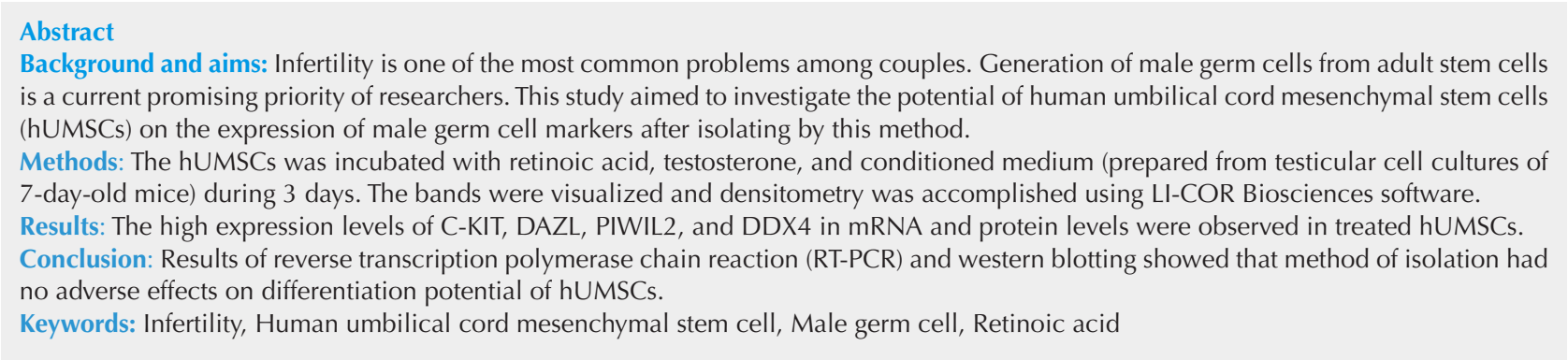

Received: 13 May 2020, Accepted: 18 October 2020, ePublished: 30 June 2021

\section{Introduction}

One of the most important research topics in regenerative medicine is the identification of differentiation mechanisms of different types of stem cells, especially differentiation into the germ line. The results of various studies led to design appropriate methods for differentiating the stem cells into male germ cells that provide a promising approach in the treatment of infertility (1-3). Among various sources of stem cells, the umbilical cord is considered as an interesting and beneficial source (4). Some of these benefits include having greater amounts of cells compared with bone marrow; having lower rate of graft-versus-host-disease; no special ethical problem; ease of collection (because umbilical cord is a waste tissue during post-partum); having lower immunological issues rather than embryonic stem cells; it is painless for mother and child; and it reduces the risk of infectious diseases transmission, especially Epstein-Barr virus and cytomegalovirus (5-7). Today, it has been known that human umbilical cord mesenchymal stem cells (hUMSCs) possess some properties of both embryonic and adult stem cells (8). Therefore, their differentiation potential is higher than MSCs, including bone marrow stem cells (9). Infertility, as one of the most common problems among couples, affects about $10 \%-15 \%$ of males and females. Approximately, half of these cases are associated with males, many of whom suffer from oligospermia or azoospermia. Other factors that affect male infertility include increased apoptosis, stress, and excessive use of glucocorticoids $(10,11)$. For infertility treatment, extensive research and therapeutic methods such as hormone therapy, in vitro fertilization, intracytoplasmic sperm injection, embryo, and ovule or sperm cryopreservation have been carried out (12). In recent decades, the scientists used different sources of stem cells such as embryonic stem cells, bone marrow stem cells, pancreatic stem cells, and stem cells derived from fetal porcine skin for in vitro differentiation toward germ cells. The ethical issues related to the use of embryonic stem cells and the probability of various tumors generation have caused scientists to focus on adult stem cells $(2,3)$. For the first time in 2006, the differentiation of mouse bone marrow MSCs into male germ cells was

C 2021 The Author(s); Published by Shahrekord University of Medical Sciences. This is an open-access article distributed under the terms of the Creative Commons Attribution License (http://creativecommons.org/licenses/by/4.0), which permits unrestricted use, distribution, and reproduction in any medium, provided the original work is properly cited. 
demonstrated in the presence of retinoic acid (12). Retinoic acid is an oxidant form of vitamin $\mathrm{A}$, which can differentiate embryonic stem cells into progenitor germ cells $(13,14)$. The present study aimed to investigate the potential of isolated mesenchymal stem cells (MSCs) by modulated explant/enzyme method (MEEM) method, as previously published (15), in expressing germ cell markers and changing morphology.

\section{Materials and Methods}

Derivation and expansion of MSCs from human umbilical cord

The isolation and expansion of hUMSCs was according to the method previously published (15). Briefly, fresh umbilical cords were conveyed to sterile phosphatebuffered saline (PBS) and rinsed to remove any vestige of blood. After preparation stages such as cutting of tissue $(10 \mathrm{~cm})$, the vessels were detached and shut in the terminal region with a sterile plastic clamp. Vascular loops and tissue fragments were partially digested by MEEM method (15). Upon incubation of explants in collagenase type I (for 3 hours) and inactivation of collagenase by Dulbecco's modified Eagle's medium-low glucose (DMEM-LG, Life Technologies, US) containing $10 \%$ fetal bovine serum (FBS, Life Technologies, US), vascular loops and partially digested explants were cultured in DMEM-LG. When the confluency of cells reached $80 \%-90 \%$, they were spilt at $1: 3$ ratio for the next experiments.

\section{Multilineage differentiation and cell surface analysis}

For identification of surface antigens, the hUMSCs $\left(1 \times 10^{6}\right)$ were stained with anti-CD105, anti-CD90, anti-CD73, anti-CD44, anti-CD45, anti-CD29, anti-CD34, anti-CD31, and HLA-DR (Abcam, UK). The related isotype controls including FITC- and PE-conjugated mouse IgG isotype antibodies were used for negative staining. Following the incubation at room temperature in the dark (20 minutes), stained cells were resuspended in $500 \mu \mathrm{L}$ PBS and analyzed by CyFlow Space flow cytometer (Partec, Germany). The histograms were generated based on computed results using Windows ${ }^{\mathrm{TM}}$-based flow cytometry software.
Preparation and incubation with differentiation medium Differentiation medium containing $10^{-5} \mathrm{M}$ retinoic acid, $1 \mathrm{mM}$ testosterone, 5\% FBS, and 50\% conditioned media were prepared. Conditioned media obtained from testes of 5- to 7-day-old Syrian male mice. Briefly, after killing, testicles of mice were isolated and triturated, then centrifuged at $1000 \mathrm{rpm}$ for 10 minutes. In the next step, supernatant was discarded and the cells were cultured. The conditioned media were gathered after 10 days and every 3 days afterward. The conditioned media were centrifuged, filtered $(0.22-\mu \mathrm{m}$ filter $)$, and stored at $-20^{\circ} \mathrm{C}$. The medium of hUMSCs monolayer was completely removed and replaced with the differentiation medium as described above. The half of old differentiation medium was replaced with a new differentiation medium every day. Also, the morphology of cells was monitored daily.

\section{RNA isolation, cDNA synthesis, and RT-PCR}

The expression of DDX4, DAZL, and PIWIL2 was investigated in comparison to the positive and negative controls using reverse transcription polymerase chain reaction (RT-PCR). Total RNA was purified and eluted in $10 \mu \mathrm{L}$ of RNase free water. Then, $1 \mu \mathrm{g}$ of total RNA was subjected to cDNA synthesis (Yektatajhizazma [YTA], Tehran, Iran) and transferred into the RT-PCR reaction. The gene-specific primers are detailed in Table 1 . The amplified products were separated on $2 \%$ agarose gel.

\section{Western blot}

The cells $\left(2 \times 10^{6}\right)$ were harvested, rinsed with PBS, and extract prepared with lysis buffer (10\% Glycerol, 10\% SDS, 25\% ß-mercaptoethanol, Tris- $\mathrm{HCl} 0.5 \mathrm{M} \mathrm{pH} \mathrm{6.8,}$ and bromophenol blue $0.5 \%$ ) containing $1 \%$ protease inhibitors. Samples were placed on ice for 60 minutes. Protein concentrations of the cell lysate were quantified by the Bradford assay. The proteins were transferred from SDS-PAGE to a PVDF membrane $(16 \mathrm{~h} / 86 \mathrm{~mA}$ and $2 \mathrm{~h} / 200 \mathrm{~mA}$ ) in a transfer buffer (Tris $25 \mathrm{mM}$, glycine $192 \mathrm{mM}$, methanol 20\%). DDX4, DAZL, and PIWIL2 were detected using primary polyclonal anti-DDX4 Ab, anti-DAZL Ab, and anti-PIWIL2 Ab (Abcam, USA) at a dilution of 1:2000 in blocking solution 5\% BSA in wash

Table 1. Gene-specific primer sequences

\begin{tabular}{|c|c|c|c|}
\hline Gene & Sequence & Annealing & Size of product \\
\hline c-kit & $\begin{array}{l}\text { F:CGTTCTGCTCCTACTGCTTCG } \\
\text { R:CCCACGCGGACTATTAAGTCT }\end{array}$ & 60 & 117 \\
\hline Oct3/4 & $\begin{array}{l}\text { F: GGAAGGTATTCAGCCAAACGACCATC } \\
\text { R: CCAGGTTGCCTCTCACTCGGTTCT }\end{array}$ & 61 & 209 \\
\hline DDX4 & $\begin{array}{l}\text { F: TCATACTTGCAGGACGAGATTTG } \\
\text { R: AACGACTGGCAGTTATTCCATC }\end{array}$ & 53 & 117 \\
\hline DAZL & $\begin{array}{l}\text { F: ATGTTGTACCTCCGGCTTATTCA } \\
\text { R: CCATTTCCAGAGGGTGGAGTA }\end{array}$ & 58 & 118 \\
\hline PIWIL2 & $\begin{array}{l}\text { F: CTGAAACGGGAAATGCTTCCA } \\
\text { R: CCTGTCCTTGCGTACCAGATTA }\end{array}$ & 60 & 78 \\
\hline GAPDH & $\begin{array}{l}\text { F: GAGTCCACTGGCGTCTTCAC } \\
\text { R: ATGACGAACATGGGGGCATC }\end{array}$ & 60 & 110 \\
\hline
\end{tabular}


buffer (TBST) at $4^{\circ}$ overnight followed by incubation with an appropriate horseradish peroxidase-conjugated secondary antibody at $37^{\circ} \mathrm{C}$ for 60 minutes and developed with a Western blotting Luminol Reagent (Thermo Fisher Scientific, USA). The bands were visualized by imaging using the LI-COR Odyssey" scanner and densitometry was accomplished using LI-COR Biosciences software.

\section{Results}

Confirmation of MSCs properties

At first, the cells were seeded in six-well plates $\left(2 \times 10^{4}\right.$ cells /well) with complete media to reach $90 \%$ confluency. To survey adipogenic differentiation, cells were stained with $0.3 \%$ Oil red O solution (Sigma, MI) for 30 minutes at room temperature. For osteogenic induction, cells were stained with Alizarin red S (Fluka, Buchs SG, Switzerland). To evaluate the expression of some major genes associated with the mesenchymal phenotype, the expression of four markers including CD105, CD90, CD73, and CD44 was confirmed. Also, no expression of hematopoietic stem cell markers such as CD45, CD34, and endothelial cell marker CD31 or HLA-DR verified (Figure 1).

\section{Morphological alteration followed by treatment}

The morphology of treated cells was observed every day. After 24 hours, the first morphological changes appeared. After 48 hours, severe morphological changes including rounding, elongation, and narrowing were generated on one side of the cytoplasm. At 72 hours, the morphological changes resulted in the formation of cells with a long cytoplasm and central rounded (Figure 2).

Expression of germ cell-specific markers in mRNA and protein levels

At day 3 after treatment with conditioned media as described above, the expression of C-KIT, DAZL, PIWIL2, DDX4, and OCT3/4 in treated and untreated hUMSCs was detected by RT-PCR or Western blot analysis. The result of RT-PCR showed the high expression level of C-KIT, DAZL, PIWIL2, and DDX4 mRNA in treated hUMSCs compared to negative controls (Figure 3). However, the expression level of OCT3/4 decreased. The expression alteration of DAZL, PIWIL2, and DDX4 verified using Western blot at the protein level (Figure 4).

\section{Discussion}

According to our results, it seems that hUMSCs may be able to differentiate into precursors of the male germ cells in the presence of combined effects of retinoic acid, testosterone, and conditioned media within 3 days. Also, some germ cell markers including C-KIT, DAZL, PIWIL2, and DDX4 can up-regulate under conditions as mentioned above. Nayernia et al showed that during 14 to 21 days, bone marrow MSCs can differentiate into gonadal precursors. In our study, decreasing the differentiation time to 3 days may be due to the source of MSCs or concentration of retinoic acid, which has been used in many previous studies as $10^{-6} \mathrm{M}$; but in our study, the concentration was $10^{-5} \mathrm{M}$. Undoubtedly, further investigation should be required in this respect. Also, additional evaluations should be well-planned for determining the precise step of differentiation (16). Generating human germ-like cells from some MSCs (e.g., bone marrow MSCs and umbilical or Wharton's jelly-derived MSCs) is largely documented (17-21), and the efficacy of the combined use of retinoic acid and gonadal conditioned media has already been known (22-24). In this research, we compared the potential of isolated MSCs by MEEM method for the expression of germ cell markers and changing the morphology with previous study. According to the literature, the expression of DDX4 is restricted to the germ line. Typically, DDX4 is expressed in human during the early stages of migration; following a decrease in the spermatogenesis stage, it has a poor to moderate expression in the spermatogonial stage. Finally, in spermatocytes and spermatids, the expression of DDX4 is greatly increased, but not in spermatozoa (25).
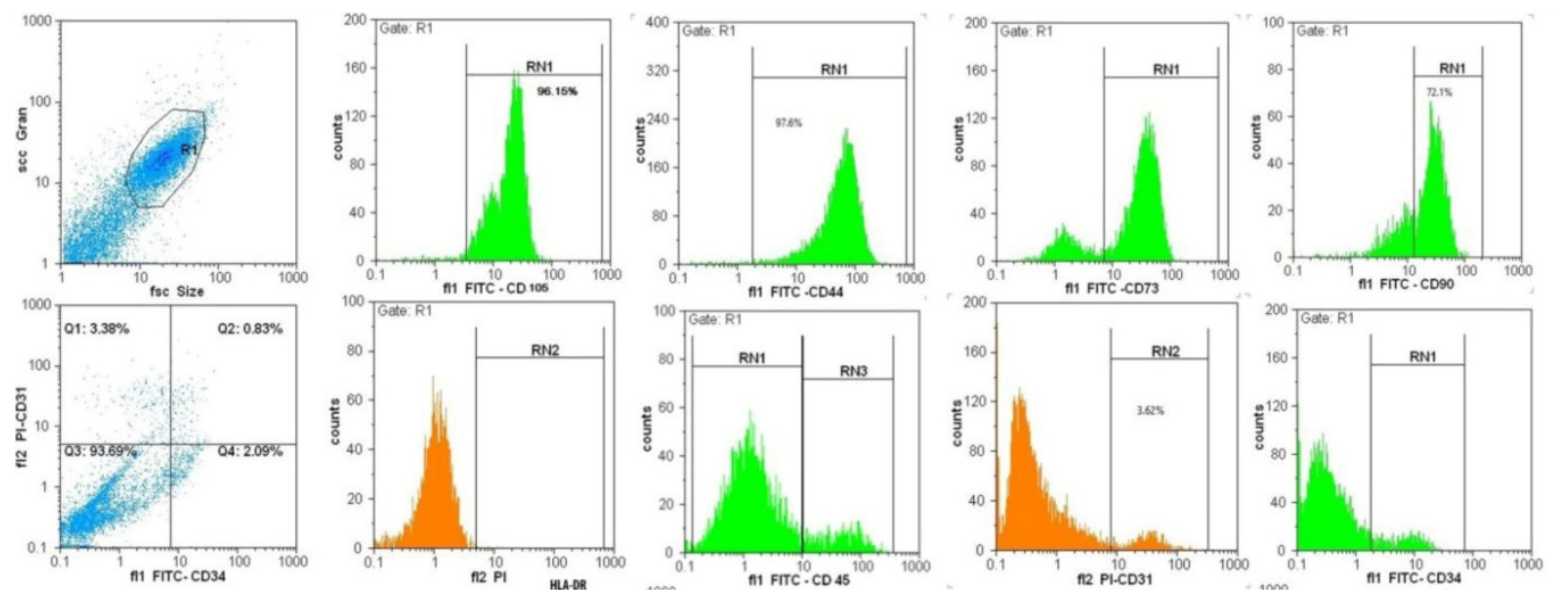

Figure1. Flow cytometry-based immunophenotyping of umbilical cord mesenchymal stem cells derived by MEEM. Cells are prominently positive for CD105, CD44, CD73, and CD90 and negative for HLADR, hematopoietic surface cell markers CD45, CD34, and endothelial cell surface antigen CD31. 

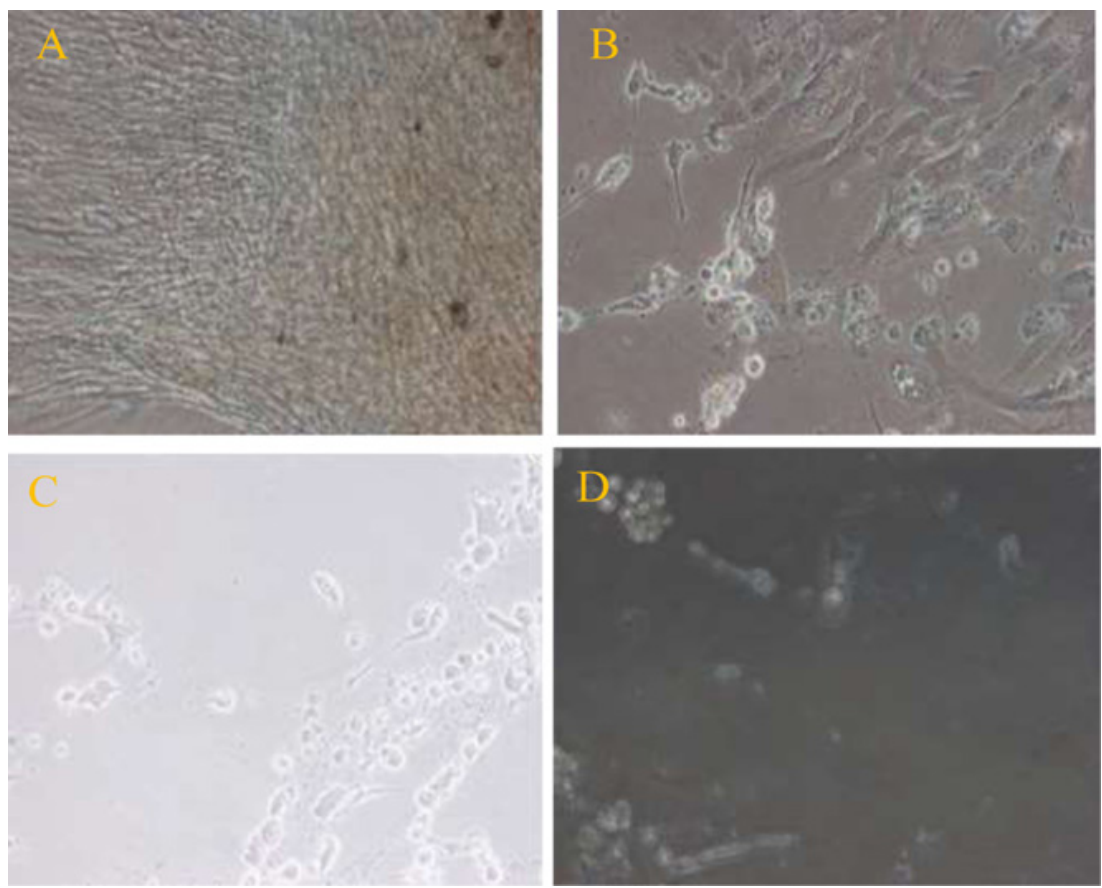

Figure 2. Morphological changes of hUMSCs following treatment. Untreated hUMSCs (A). The morphological changes began after $24 \mathrm{~h}$ including narrowing on one side of the cells (B). The morphological changes after $48 \mathrm{~h}$ are very severe (C). Severe morphological changes including rounding, elongation and narrowing on one side of the cytoplasm were seen in most of the cells, after $72 \mathrm{~h}$ (D).

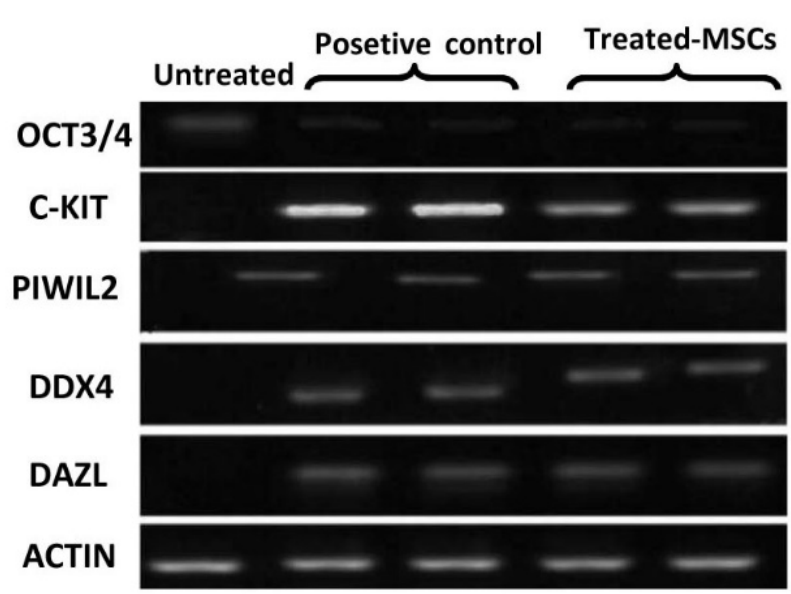

Figure 3. RT-PCR analysis of DAZL, PIWIL2, DDX4, C-KIT, and OCT3/4. Positive control: Human testicular tissue. Treated-MSCs: Treated hUMSCs after $72 \mathrm{~h}$.

In our study, DDX4 expression was confirmed at the level of protein and RNA. However, the expression of PIWIL2 in primary spermatocytes is partially, but it significantly increased in spermatids (26). Also, DAZL is initially expressed in the primary germ cells, then continued during spermatogenesis (27). Since doubling time of bone marrow stromal cells is different from hUMSCs (96 hours vs. 36 hours), the potential of differentiation of them into the germ line may also be different (28). Our results indicated the upregulation of specific genes including DAZL, PIWIL2, and DDX4, which confirmed the differentiation of hUMSCs toward germ cells. Downregulated expression of OCT $3 / 4$ (as a stemness gene) determined the transferring from stem cell toward next differentiation stages. On the other hand, the upregulated expression of C-KIT represents the differentiated MSCs. Previously, human and mouse embryonic stem cells, bone marrow, or pancreas were used to differentiate into the germ cell (122930). Recently, the use of MSCs in regeneration medicine has increased in various studies due to the clinical importance and numerous advantages. Growing evidence suggests that MSCs may be a suitable candidate for in vitro germ cell generation (31-33). In this regard, we reported that isolated hUMSCs by MEEM method might be an easily obtained source to derive germ cells; however, further information and research would be required to support this claim.

Conclusion

The results of current study showed that our method

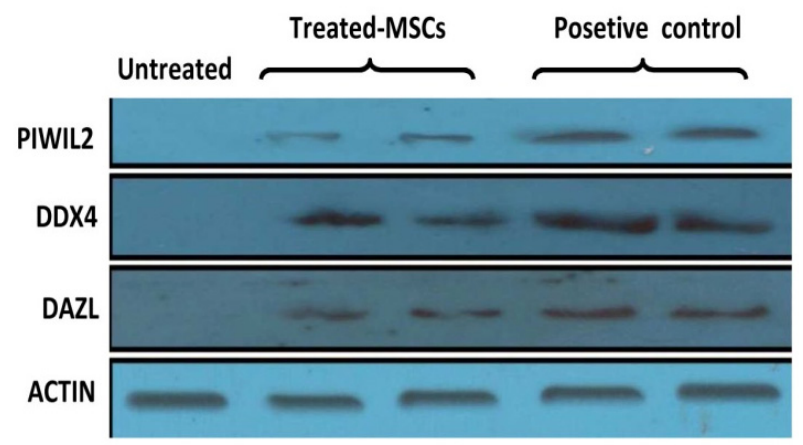

Figure 4. Investigation of PIWIL2, DDX4, and DAZL expression by western blotting after $72 \mathrm{~h}$. Positive Control: Human testicular tissue. Treated-MSCs: Treated hUMSCs after 72 h. Actin was used as a control. 
of isolation had no adverse effects on differentiation potential of hUMSCs.

Conflict of Interests

The authors declare that they have no conflict of interests.

Ethical Approval

The study protocol was approved by the Research Ethics Committee of Shahrekord University of Medical Sciences (SKUMS), which was according to the Helsinki Declaration (IR. SKUMS.REC.1394.249).

\section{Authors' Contribution}

MBD designed and directed the study. AS, AMG, and SR carried out the experiments and wrote the manuscript. All authors discussed the results and contributed to the final manuscript.

\section{Funding/Support}

This study was supported by the Deputy of Research and Technology of SKUMS [grant number: 2092].

\section{Acknowledgments}

The authors would like to express sincere thanks to the staff of Cellular and Molecular Research Center of Basic Health Sciences Institute of SKUMS for their cooperation.

\section{References}

1. Lodi D, Iannitti T, Palmieri B. Stem cells in clinical practice: applications and warnings. J Exp Clin Cancer Res. 2011;30(1):9. doi: 10.1186/1756-9966-30-9.

2. Valli H, Phillips BT, Shetty G, Byrne JA, Clark AT, Meistrich ML, et al. Germline stem cells: toward the regeneration of spermatogenesis. Fertil Steril. 2014;101(1):3-13. doi: 10.1016/j.fertnstert.2013.10.052.

3. Fang F, Li Z, Zhao Q, Li H, Xiong C. Human induced pluripotent stem cells and male infertility: an overview of current progress and perspectives. Hum Reprod. 2018;33(2):188-95. doi: 10.1093/humrep/dex369.

4. Azzopardi JI, Blundell R. Umbilical cord stem cells. Stem Cell Discov. 2018;8(1):83115. doi: 10.4236/scd.2018.81001.

5. Riordan NH, Hincapié ML, Morales I, Fernández G, Allen N, Leu C, et al. Allogeneic human umbilical cord mesenchymal stem cells for the treatment of autism spectrum disorder in children: safety profile and effect on cytokine levels. Stem Cells Transl Med. 2019;8(10):1008-16. doi: 10.1002/sctm.19-0010.

6. Strong A, Gračner T, Chen P, Kapinos K. On the value of the umbilical cord blood supply. Value Health. 2018;21(9):107782. doi: 10.1016/j.jval.2018.03.003.

7. Shojaeian A, Mehri-Ghahfarrokhi A, Banitalebi-Dehkordi M. Migration gene expression of human umbilical cord mesenchymal stem cells: a comparison between monophosphoryl lipid A and supernatant of Lactobacillus acidophilus. Int J Mol Cell Med. 2019;8(2):154-60. doi: 10.22088/ijmcm.bums.8.2.154.

8. Kim DW, Staples M, Shinozuka K, Pantcheva P, Kang SD, Borlongan CV. Wharton's jelly-derived mesenchymal stem cells: phenotypic characterization and optimizing their therapeutic potential for clinical applications. Int J Mol Sci. 2013;14(6):11692-712. doi: 10.3390/ijms140611692.

9. Kim HJ, Park JS. Usage of human mesenchymal stem cells in cell-based therapy: advantages and disadvantages. Dev
Reprod. 2017;21(1):1-10. doi: 10.12717/dr.2017.21.1.001.

10. Karabulut S, Keskin İ, Kutlu P, Delikara N, Atvar Ö, Öztürk MI. Male infertility, azoozpermia and cryptozoospermia incidence among three infertility clinics in Turkey. Turk J Urol. 2018;44(2):109-13. doi: 10.5152/tud.2018.59196.

11. Latchoumycandane C, Vaithinathan S, D'Cruz SC, Mathur PP. Apoptosis and male infertility. In: Parekattil S, Esteves S, Agarwal A, eds. Male Infertility. Cham: Springer; 2020. p. 479-86. doi: 10.1007/978-3-030-32300-4_37.

12. Nayernia K, Lee JH, Drusenheimer N, Nolte J, Wulf G, Dressel R, et al. Derivation of male germ cells from bone marrow stem cells. Lab Invest. 2006;86(7):654-63. doi: 10.1038/labinvest.3700429.

13. Luo Y, Xie L, Mohsin A, Ahmed W, Xu C, Peng Y, et al. Efficient generation of male germ-like cells derived during co-culturing of adipose-derived mesenchymal stem cells with Sertoli cells under retinoic acid and testosterone induction. Stem Cell Res Ther. 2019;10(1):91. doi: 10.1186/ s13287-019-1181-5.

14. Busada JT, Geyer CB. The role of retinoic acid (RA) in spermatogonial differentiation. Biol Reprod. 2016;94(1):110. doi: 10.1095/biolreprod.115.135145.

15. Banitalebi Dehkordi M, Madjd Z, Hashemzadeh Chaleshtori M, Meshkani R, Nikfarjam L, Kajbafzadeh AM. A simple, rapid, and efficient method for isolating mesenchymal stem cells from the entire umbilical cord. Cell Transplant. 2016;25(7):1287-97. doi: 10.3727/096368915x582769.

16. Sandlow JI, Feng HL, Sandra A. Localization and expression of the c-kit receptor protein in human and rodent testis and sperm. Urology. 1997;49(3):494-500. doi: 10.1016/s00904295(96)00494-3.

17. Malekmohamadi N, Abdanipour A, Ghorbanlou M, Shokri S, Shirazi R, Dimitriadis E, et al. Differentiation of bone marrow derived mesenchymal stem cells into male germlike cells in co-culture with testicular cells. Endocr Regul. 2019;53(2):93-9. doi: 10.2478/enr-2019-0011.

18. Huang P, Lin LM, Wu XY, Tang QL, Feng XY, Lin GY, et al. Differentiation of human umbilical cord Wharton's jelly-derived mesenchymal stem cells into germ-like cells in vitro. J Cell Biochem. 2010;109(4):747-54. doi: 10.1002/ jcb.22453.

19. Kaviani M, Ezzatabadipour M, Nematollahi-Mahani SN, Salehinejad P, Mohammadi M, Kalantar SM, et al. Evaluation of gametogenic potential of vitrified human umbilical cord Wharton's jelly-derived mesenchymal cells. Cytotherapy. 2014;16(2):203-12. doi: 10.1016/j.jcyt.2013.10.015.

20. Latifpour M, Shakiba Y, Amidi F, Mazaheri Z, Sobhani A. Differentiation of human umbilical cord matrix-derived mesenchymal stem cells into germ-like cells. Avicenna J Med Biotechnol. 2014;6(4):218-27.

21. Dissanayake D, Patel H, Wijesinghe PS. Differentiation of human male germ cells from Wharton's jelly-derived mesenchymal stem cells. Clin Exp Reprod Med. 2018;45(2):75-81. doi: 10.5653/cerm.2018.45.2.75.

22. Amidi F, Ataie Nejad N, Agha Hoseini M, Nayernia K, Mazaheri Z, Yamini N, et al. In vitro differentiation process of human Wharton's jelly mesenchymal stem cells to male germ cells in the presence of gonadal and non-gonadal conditioned media with retinoic acid. In Vitro Cell Dev Biol Anim. 2015;51(10):1093-101. doi: 10.1007/s11626015-9929-4.

23. Ghaem Maghami R, Mirzapour T, Bayrami A. 
Differentiation of mesenchymal stem cells to germ-like cells under induction of Sertoli cell-conditioned medium and retinoic acid. Andrologia. 2018;50(3):e12887. doi: 10.1111/and.12887.

24. Salem M, Mirzapour T, Bayrami A, Sagha M. Germ cell differentiation of bone marrow mesenchymal stem cells. Andrologia. 2019;51(4):e13229. doi: 10.1111/and.13229.

25. Toyooka Y, Tsunekawa N, Takahashi Y, Matsui Y, Satoh M, Noce T. Expression and intracellular localization of mouse Vasa-homologue protein during germ cell development. Mech Dev. 2000;93(1-2):139-49. doi: 10.1016/s09254773(00)00283-5.

26. Carmell MA, Girard A, van de Kant HJ, Bourc'his D, Bestor TH, de Rooij DG, et al. MIWI2 is essential for spermatogenesis and repression of transposons in the mouse male germline. Dev Cell. 2007;12(4):503-14. doi: 10.1016/j.devcel.2007.03.001.

27. Ruggiu M, Saunders PT, Cooke HJ. Dynamic subcellular distribution of the DAZL protein is confined to primate male germ cells. J Androl. 2000;21(3):470-7.

28. Jin HJ, Bae YK, Kim M, Kwon SJ, Jeon HB, Choi SJ, et al. Comparative analysis of human mesenchymal stem cells from bone marrow, adipose tissue, and umbilical cord blood as sources of cell therapy. Int J Mol Sci. 2013;14(9):17986-
8001. doi: 10.3390/ijms140917986.

29. Clark AT, Bodnar MS, Fox M, Rodriquez RT, Abeyta MJ, Firpo MT, et al. Spontaneous differentiation of germ cells from human embryonic stem cells in vitro. Hum Mol Genet. 2004;13(7):727-39. doi: 10.1093/hmg/ddh088.

30. Danner S, Kajahn J, Geismann C, Klink E, Kruse C. Derivation of oocyte-like cells from a clonal pancreatic stem cell line. Mol Hum Reprod. 2007;13(1):11-20. doi: 10.1093/molehr/gal096.

31. West FD, Shirazi R, Mardanpour P, Ozcan S, Dinc G, Hodges DH, et al. In vitro-derived gametes from stem cells. Semin Reprod Med. 2013;31(1):33-8. doi: 10.1055/s-00321331795.

32. Volarevic V, Bojic S, Nurkovic J, Volarevic A, Ljujic B, Arsenijevic N, et al. Stem cells as new agents for the treatment of infertility: current and future perspectives and challenges. Biomed Res Int. 2014;2014:507234. doi: 10.1155/2014/507234.

33. Ghasemzadeh-Hasankolaei M, Baghaban Eslaminejad M, Sedighi-Gilani M. Derivation of male germ cells from ram bone marrow mesenchymal stem cells by three different methods and evaluation of their fate after transplantation into the testis. In Vitro Cell Dev Biol Anim. 2016;52(1):4961. doi: 10.1007/s11626-015-9945-4. 